\title{
Swallow syncope: a case report and review of literature
}

\author{
Kelvin Shenq Woei Siew ${ }^{1 *}$ (D), Maw Pin Tan², Ida Normiha Hilmi ${ }^{3}$ and Alexander Loch ${ }^{1}$
}

\begin{abstract}
Background: Swallow or deglutition syncope is an unusual type of neurally-mediated syncope associated with lifethreatening bradyarrhythmia and hypotension. It is a difficult condition to diagnose with commonly delayed diagnosis and management. There is lack of review articles that elucidate the basic demographics, clinical characteristics and management of this rare condition. This publication systematically reviews the 101 case reports published since 1793 on swallow syncope.

Case presentation: A 59-year-old man presented with the complaint of recurrent dizziness associated with meals. A 24-h ambulatory ECG recording confirmed an episode of p-wave asystole at the time of food intake. Oesophagogastroduodenoscopy with balloon inflation in the mid to lower oesophagus resulted in a $5.6 \mathrm{~s}$ sinus pause. The patient's symptoms resolved completely following insertion of a permanent dual chamber pacemaker.

Conclusions: Swallow syncope is extremely rare, but still needs to be considered during diagnostic workup. It is commonly associated with gastro-intestinal disease. Permanent pacemaker implantation is the first line treatment.
\end{abstract}

Keywords: Swallow, Syncope, Deglutition, Bradycardia, AV block, Pacemaker

\section{Background}

Swallow syncope is a rare cause of a neurally mediated syncope that is frequently associated with life-threatening bradyarrhythmia [1]. The underlying mechanism is believed to be an exaggerated vagal stimulation during swallowing resulting in suppression of the cardiac conduction system. Swallow syncope has been reported in all age groups and occurs with or without underlying esophageal or cardiac pathology. A diagnosis of swallow syncope is frequently missed by physicians, often resulting in delayed diagnosis and treatment. The first case of swallow syncope was reported by Spens in 1793 [2]. Since then, another 117 cases have been reported in the literature.

We present a case of recurrent swallow syncope with a review and summary of the entire literature available regarding this rare condition.

\footnotetext{
* Correspondence: ksiewsw@gmail.com

'Department of Medicine/Cardiology, University Malaya Medical Centre,

Kuala Lumpur, Malaysia

Full list of author information is available at the end of the article
}

\section{Case presentation}

A 59-year-old Chinese male presented with a 6-month history of intermittent dizziness. The dizziness occurred exclusively at meal times and was worst when swallowing large quantities of solid food, such as rice or bread. He initially was symptom free when consuming smaller quantities of solids or fluids, but his condition worsened progressively with presyncopal events occurring even while eating smaller quantities of solid food. The patient described a sensation of increasing difficulty in swallowing despite reducing the size of his meals. He denied any associated syncope or seizures. His past medical history and physical examination were unremarkable and blood investigations were within normal limits. Echocardiography revealed a structurally normal heart with normal systolic and diastolic function. 24-h electrocardiogram (ECG) monitoring recorded a sinus pause of $4.5 \mathrm{~s}$ at the time the patient had his meal (Fig. 1). A provisional diagnosis of swallow syncope was made and a permanent pacemaker (PPM) implantation was scheduled.

Tilt table testing prior to pacemaker insertion resulted in a hypotensive response $5 \mathrm{~min}$ after provocation with 400 micrograms of sublingual glycerin trinitrate administered 


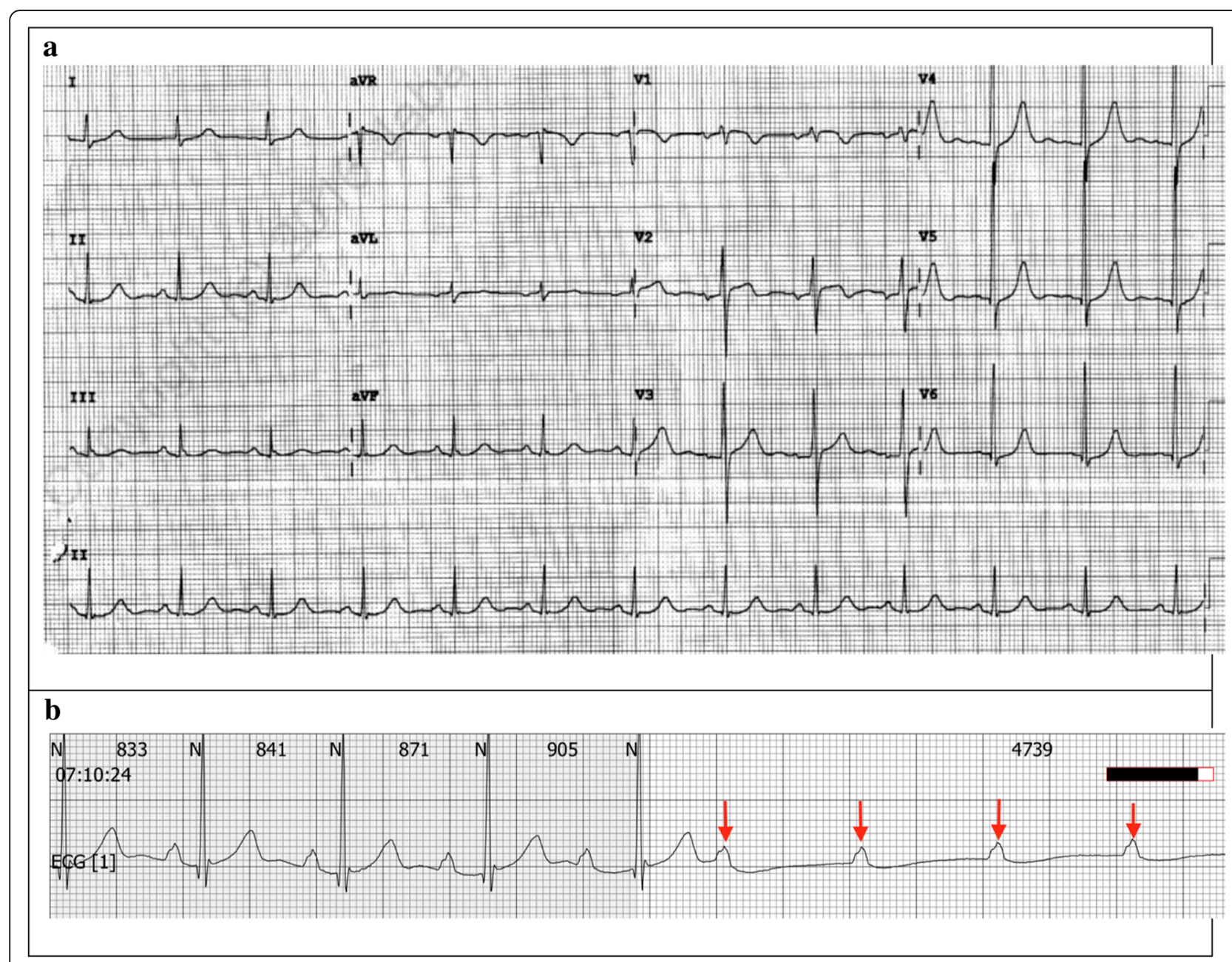

Fig. 1 a 12-lead electrocardiogram with normal sinus rhythm during non-meal times. b 4.5 s episode of non-conducted p-waves during breakfast on a 24-h ECG. Arrow denotes p-waves

sublingually, with reproduction of symptoms of syncope. The minimal blood pressure was $32.9 / 29.2 \mathrm{mmHg}$ and the heart rate $75.3 \mathrm{bpm}$. No asystole was observed during tilt table testing (Fig. 2).

The patient's symptoms resolved completely after implantation of a dual chamber PPM. A diagnostic workup to exclude gastrointestinal disease was performed. A barium swallow test was normal and effectively ruled out achalasia. The oesophagus appeared healthy with no structural disease on oesophagogastroduodenoscopy (OGD). The pacemaker was continuously interrogated during the OGD. Increased pacing requirements were noted when the endoscope was advanced into the esophagus (Fig. 3b). Subsequently, a $20 \mathrm{~mm}$ diameter TTS (through-the-scope), $\mathrm{CRE}^{\mathrm{ma}}$ (controlled radial expansion) balloon (Boston scientific) was sequentially inflated in the proximal, mid and distal esophagus while the pacemaker was programmed "OFF" to assess the physiologic response. Inflation in both distal and mid oesophagus resulted in significant sinus pauses of up to $5.6 \mathrm{~s}$ (Fig. 3c) confirming the cardio-inhibitory response to oesophageal distension as the underlying pathophysiological mechanism of this patient's syncopal events.

\section{Discussion}

Swallow syncope is more common in males $(59.4 \%, n=$ $60)$, and in the older age group (55.4\%, $n=56$, more than 60 years old). The mean age at presentation was 57.5 years with the youngest patient described in the literature being 5 years old [3] and the eldest 89 years old [4]. All of the patient presented with either presyncope or syncope. Only one patient was diagnosed incidentally, when a high degree atrioventricular (AV) block associated with meal times was found during a diagnostic workup for lung carcinoma [5]. Swallow syncope is strongly associated with gastrointestinal diseases $(32.7 \%$, $n=33)$. Hiatal hernia $(18.8 \%, n=19)$, oesophageal stricture $(3 \%, n=3)$, achalasia $(3 \%, n=3)$ and oesophageal 


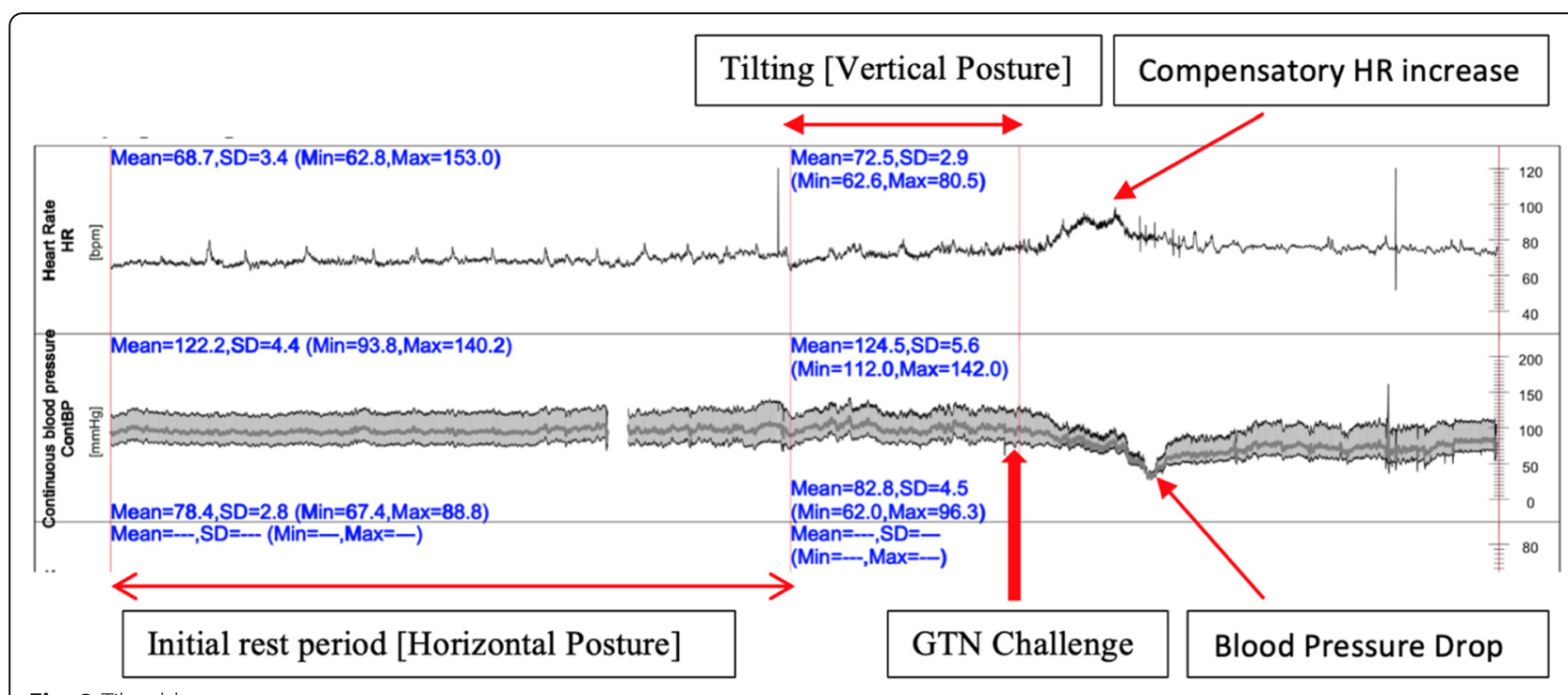

Fig. 2 Tilt table test

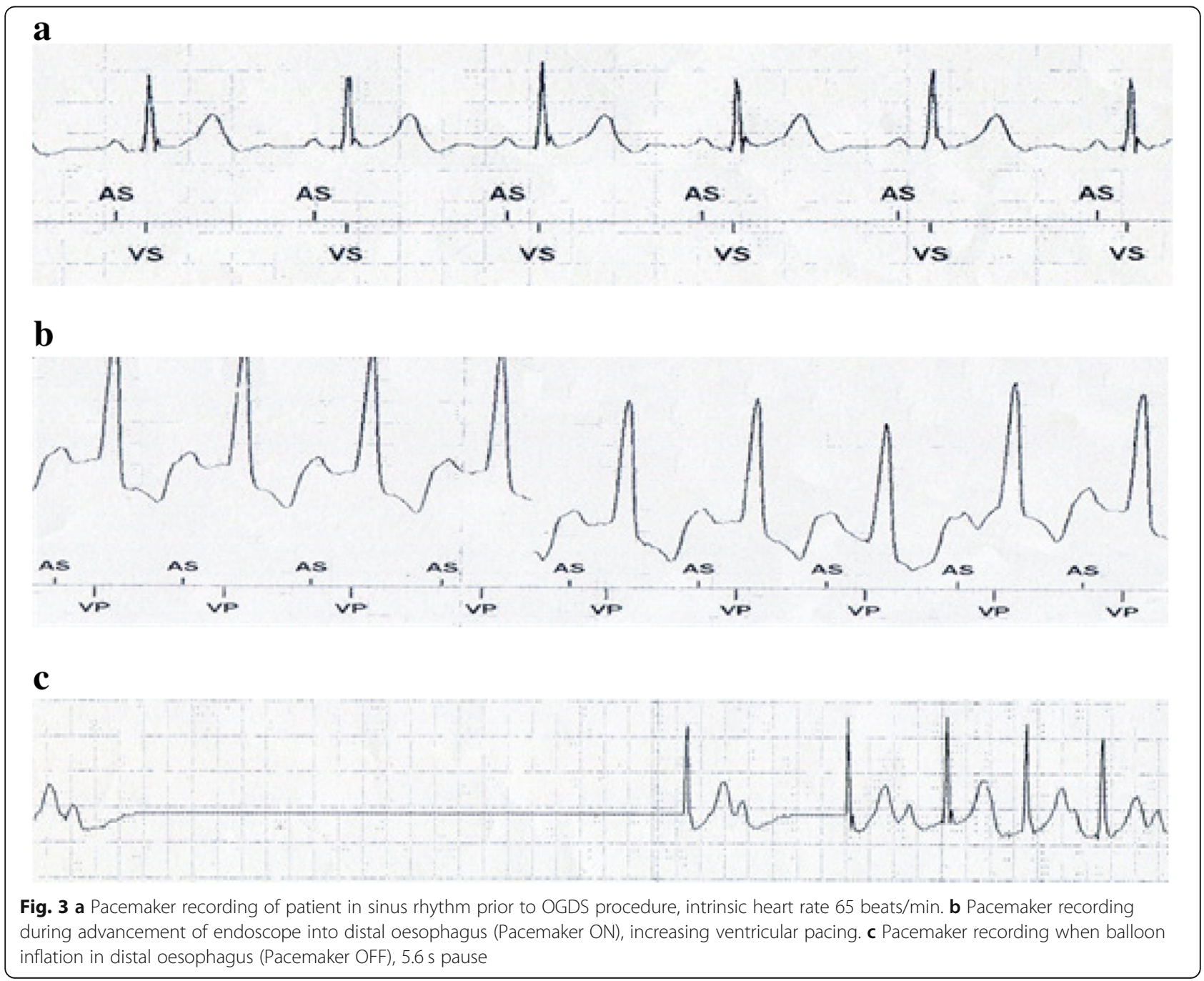




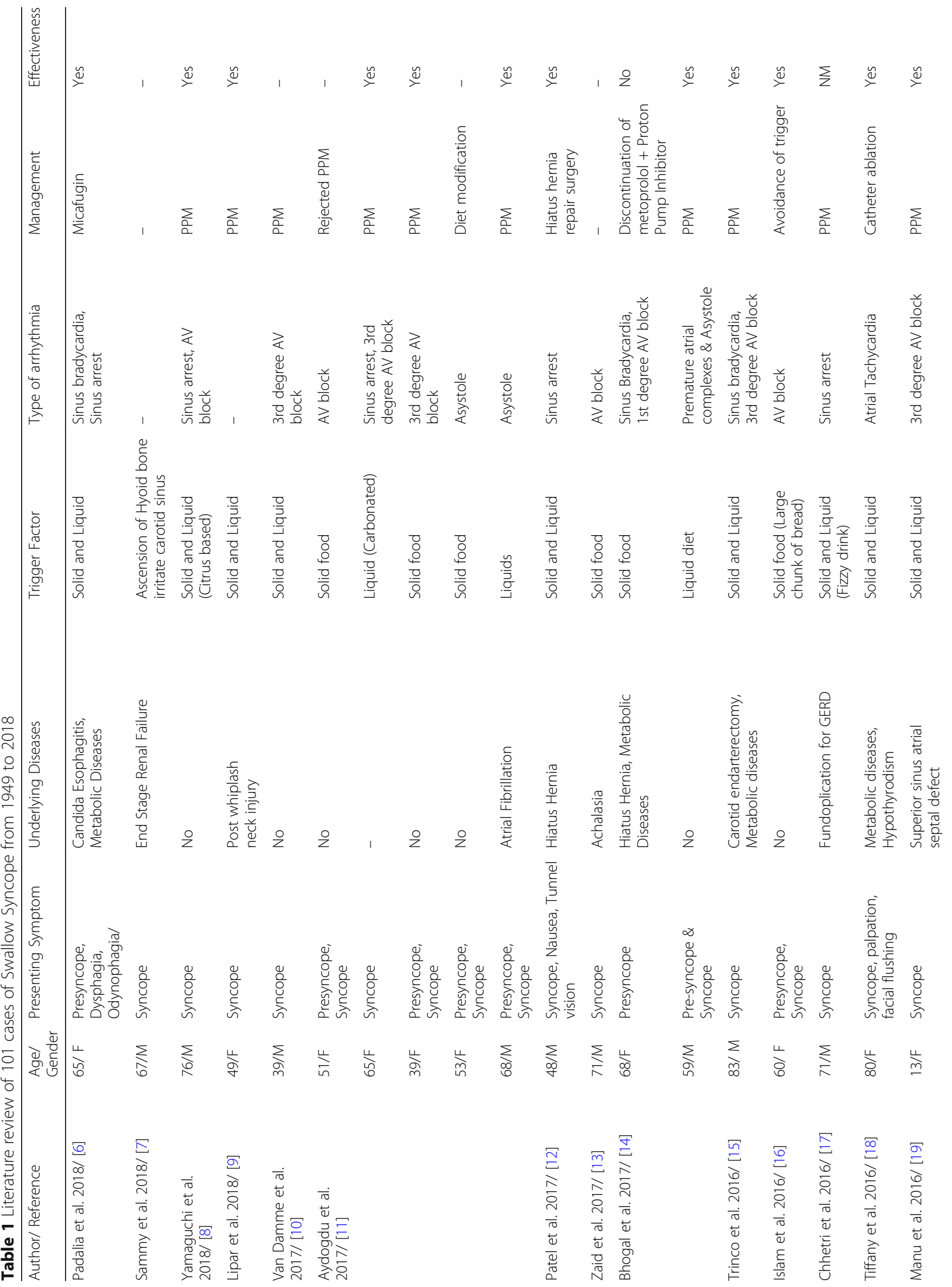




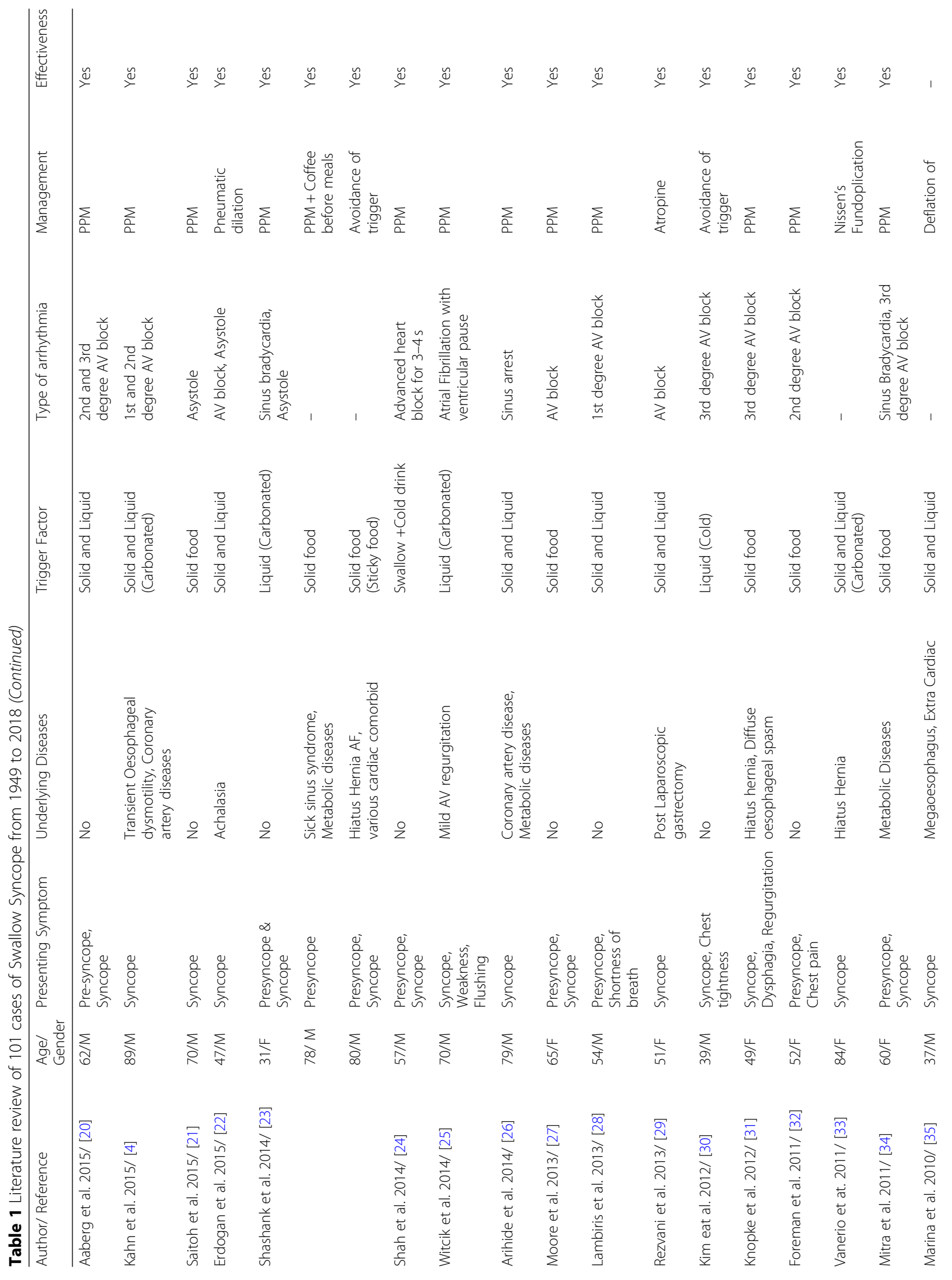




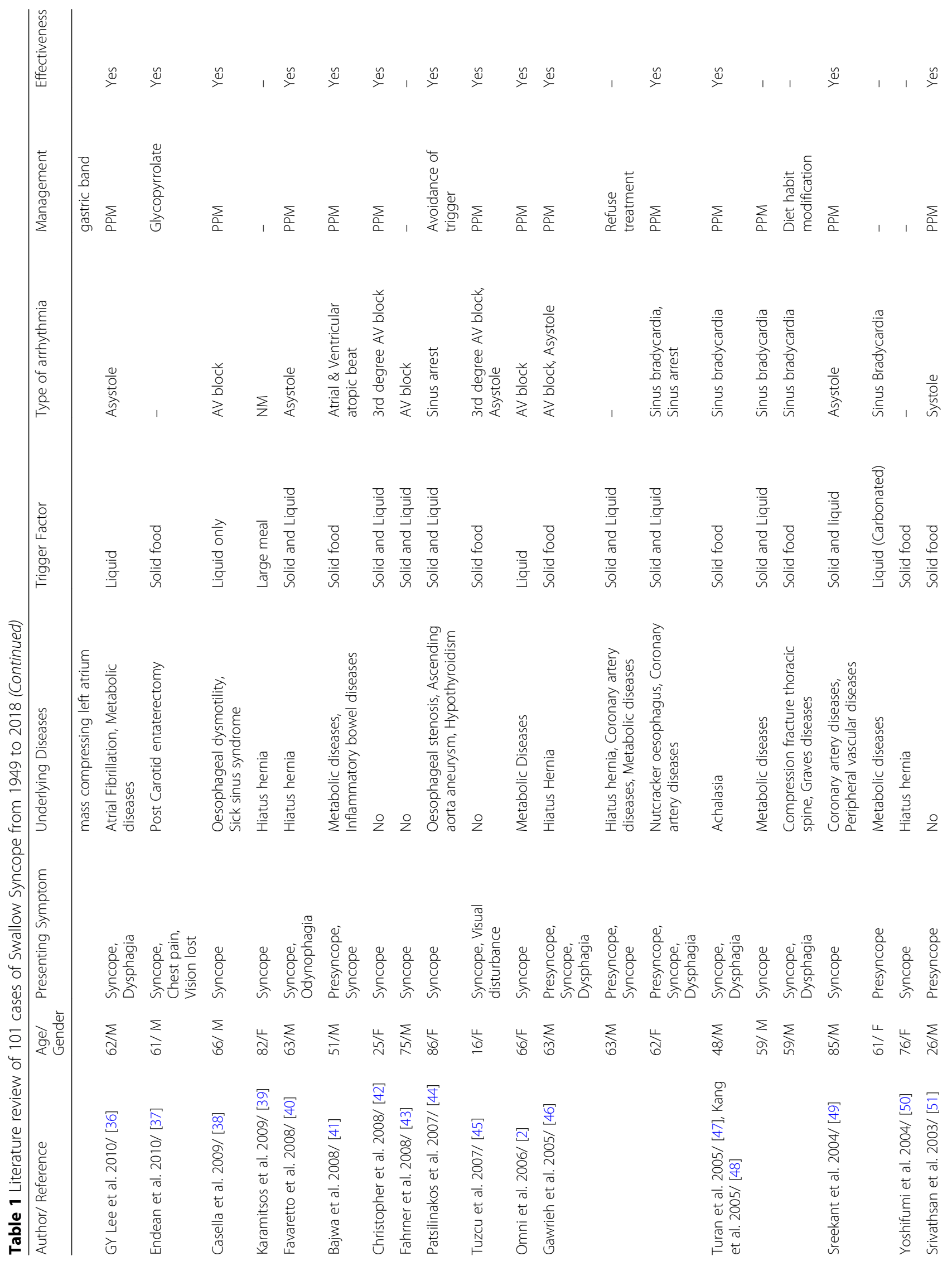




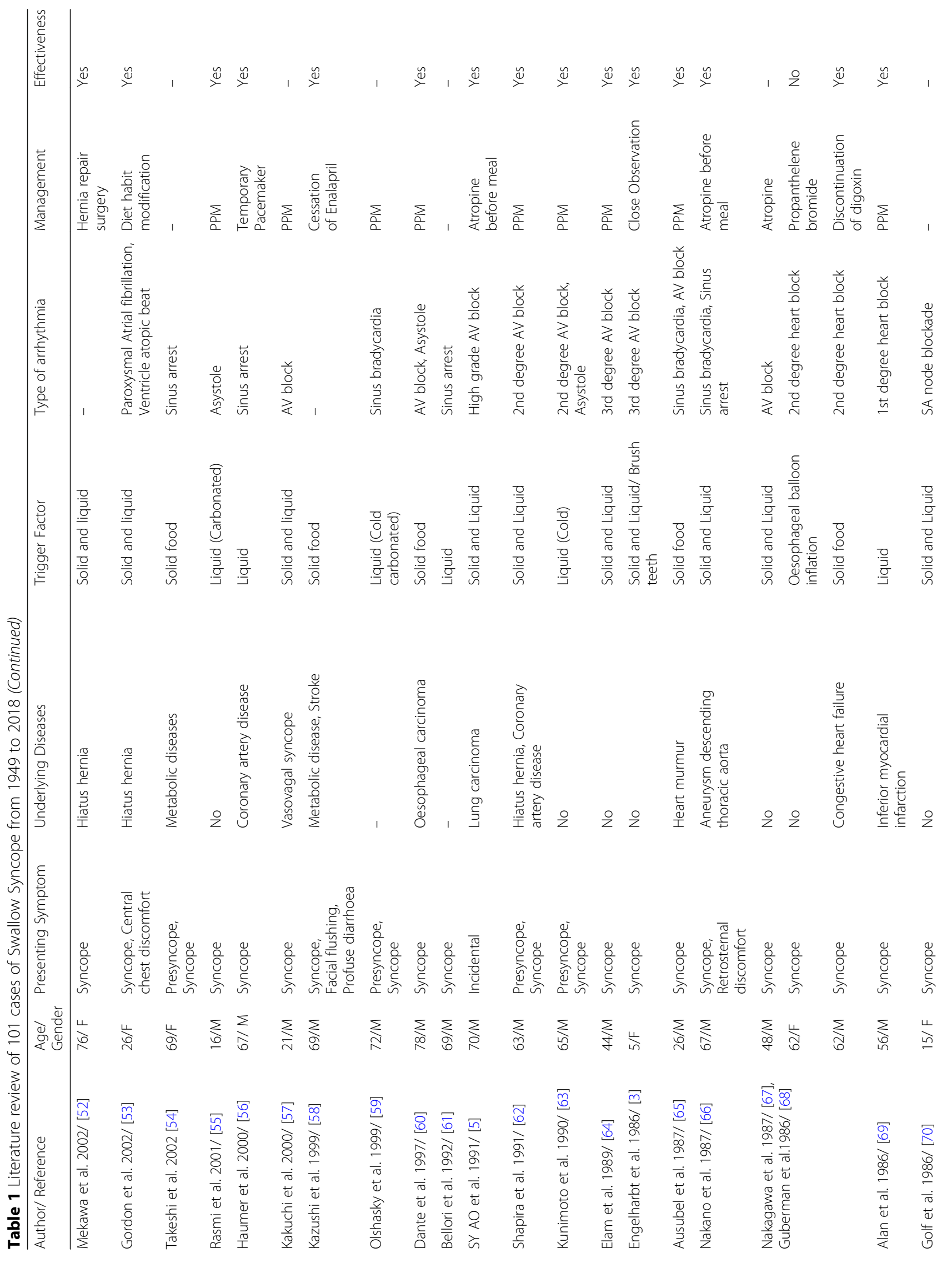




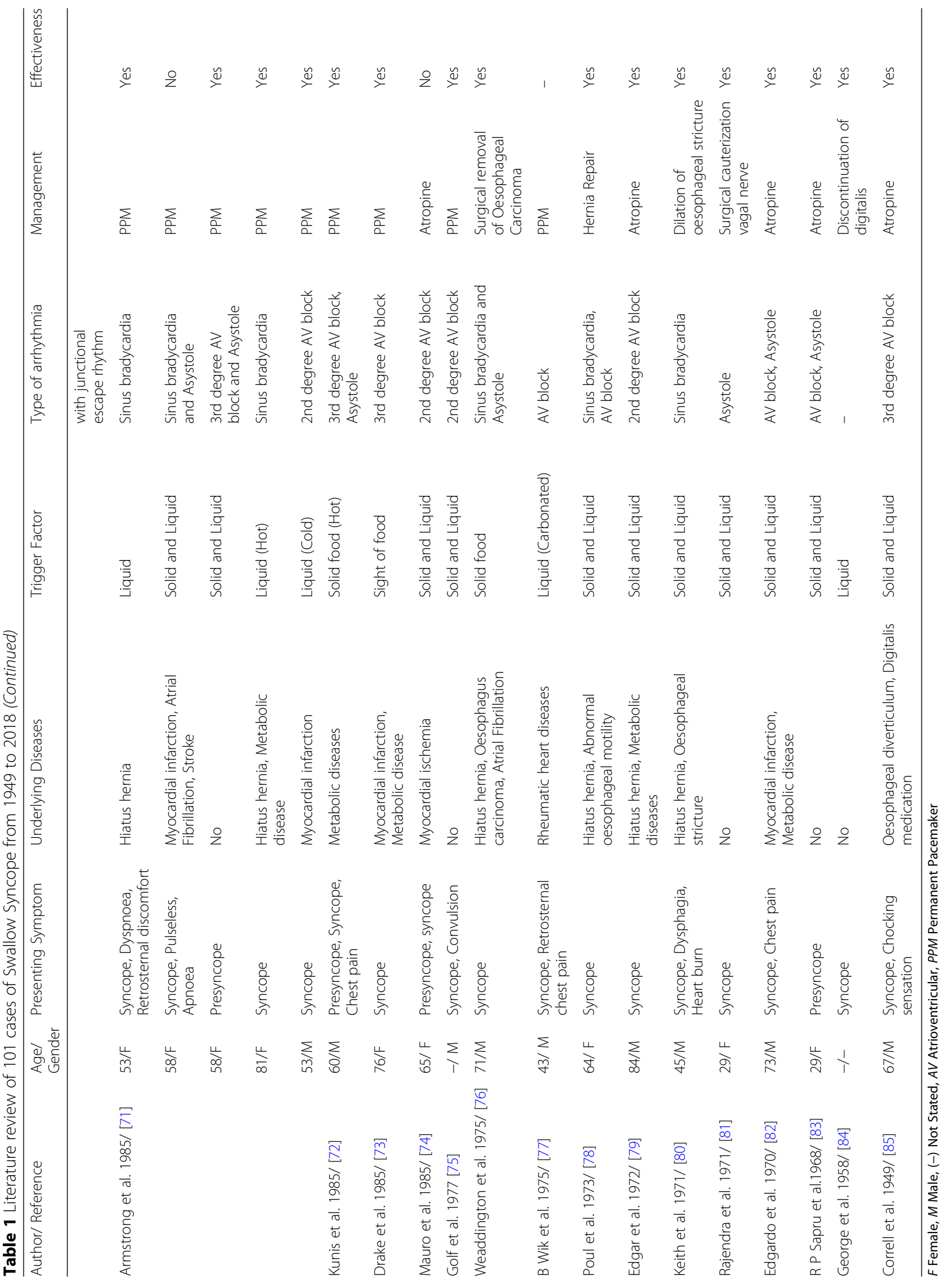


Table 2 Characteristics of 101 reviewed cases of swallow syncope

\begin{tabular}{|c|c|c|}
\hline & $\begin{array}{l}\text { Frequency } \\
(n=)\end{array}$ & $\begin{array}{l}\text { Percentage } \\
(\%)\end{array}$ \\
\hline \multicolumn{3}{|l|}{ Age Group $(n=101)$} \\
\hline Childhood/Adolescent [0-19 years] & 6 & 5.9 \\
\hline Younger adults [20-59 years] & 37 & 36.6 \\
\hline Older adults [60 years and above] & 56 & 55.4 \\
\hline Not stated & 2 & 2.0 \\
\hline \multicolumn{3}{|l|}{ Gender $(n=101)$} \\
\hline Male & 60 & 59.4 \\
\hline Female & 40 & 39.6 \\
\hline Not Stated & 1 & 1.0 \\
\hline \multicolumn{3}{|l|}{ Clinical Presentation $(n=101)$} \\
\hline Syncope & 100 & 99.0 \\
\hline Dysphagia & 12 & 11.9 \\
\hline Asymptomatic (incidental diagnosis) & 1 & 1.0 \\
\hline \multicolumn{3}{|l|}{ Underlying Diseases $(n=100)$} \\
\hline Gastrointestinal Diseases & 34 & 33.7 \\
\hline Hiatal Hernia & 19 & 18.8 \\
\hline Achalasia & 3 & 3.0 \\
\hline Esophageal stricture & 3 & 3.0 \\
\hline Cardiac Diseases & 33 & 32.7 \\
\hline Coronary artery diseases & 14 & 13.9 \\
\hline Atrial Fibrillation & 5 & 5.0 \\
\hline Sick Sinus Syndrome & 3 & 3.0 \\
\hline Comorbidities $^{\mathrm{a}}$ & 28 & 27.7 \\
\hline \multicolumn{3}{|l|}{ Trigger Factor $(n=101)$} \\
\hline Any (Solid and Liquid) & 55 & 54.5 \\
\hline Solid only & 23 & 22.8 \\
\hline Liquid only & 23 & 22.8 \\
\hline \multicolumn{3}{|l|}{ Type of Arrhythmia $(n=101)$} \\
\hline Sinus Dysfunction ${ }^{\mathrm{b}}$ & 34 & 33.7 \\
\hline Atrioventricular Dysfunction $^{c}$ & 35 & 34.7 \\
\hline $\begin{array}{l}\text { Combination Sinus and AV } \\
\text { Dysfunction }\end{array}$ & 16 & 15.8 \\
\hline Not Stated & 13 & 12.9 \\
\hline Others $^{d}$ & 3 & 3.0 \\
\hline \multicolumn{3}{|l|}{ Management $(n=101)$} \\
\hline Pacemaker Implantation & 56 & 55.5 \\
\hline Pharmacotherapy & 11 & 10.9 \\
\hline Atropine & 9 & 8.9 \\
\hline $\begin{array}{l}\text { Treatment of Underlying causative } \\
\text { factor }\end{array}$ & 16 & 15.8 \\
\hline Surgical correction of hiatal hernia & 4 & 4.0 \\
\hline Dilation of achalasia & 1 & 1.0 \\
\hline Dilation of esophageal stricture & 1 & 1.0 \\
\hline
\end{tabular}

Table 2 Characteristics of 101 reviewed cases of swallow syncope (Continued)

\begin{tabular}{lll}
\hline & $\begin{array}{l}\text { Frequency } \\
(n=)\end{array}$ & $\begin{array}{l}\text { Percentage } \\
(\%)\end{array}$ \\
\hline Conservative Management & 9 & 8.9 \\
Avoidance trigger/ diet modification & 7 & 6.9 \\
Close observation/ refused treatment & 2 & 2.0 \\
Not Stated & 9 & 8.9 \\
$\begin{array}{l}\text { Documented efficacy of resp. } \\
\text { treatment }\end{array}$ & Effective $(n=)$ & Efficacy rate \\
Pacemaker $(n=53)$ & 52 & 98.1 \\
Atropine treatment $(n=8)$ & 7 & 87.5 \\
$\begin{array}{l}\text { Surgical correction of Hiatal hernia } \\
(n=4)\end{array}$ & 4 & 100 \\
$\begin{array}{l}\text { Dilation of Achalasia }(n=1) \\
\text { Dilation of esophageal stricture }(n=1)\end{array}$ & 1 & 100 \\
$\begin{array}{l}\text { Avoidance trigger/ diet modification } \\
(n=5)\end{array}$ & 5 & 100 \\
\hline
\end{tabular}

${ }^{a}$ Comorbidities defined as hypertension or diabetes mellitus or dyslipidemia or obesity or chronic kidney disease

${ }^{\mathrm{b}}$ Sinus Bradycardia, Sinus Arrest, Asystole; ${ }^{\mathrm{c}}$ First, Second, Third degree Atrioventricular block; ${ }^{d}$ Atrial Tachycardia, Atrial Fibrillation and others

carcinoma are the most common associated gastrointestinal disorders. Thirty-three patients $(32.7 \%)$ had underlying cardiac diseases including coronary artery diseases $(13.9 \%, n=14)$, atrial fibrillation $(5 \%, n=5)$, sick sinus syndrome $(3 \%, n=3)$, aortic aneurysm, rheumatic heart disease and digitalis toxicity. Twenty-eight patients (27.7\%) had metabolic diseases like hypertension, diabetes mellitus, dyslipidaemia or obesity.

In most patients $(54.5 \%, n=55)$, any type of food - be it liquids or solids - triggered syncope. Atrioventricular conduction blocks $(34.7 \%, n=35)$ including first, second and third-degree AV blocks are the most common electrophysiological problems, followed closely by sinus node dysfunctions $(33.7 \%, n=34)$ including sinus bradycardia, sinus arrest and asystole. Second degree AV block, complete heart block (=3rd degree AV block) and asystole were the most frequently reported bradyarrhythmia in the literature. However, there are several cases where both sinus and atrioventricular dysfunction concurred. Paroxysmal atrial fibrillation and atrial tachycardia were rare causes of syncope. Table 1 .

Pacemaker implantation is the most popular treatment modality. More than half of the patients $(55.5 \%, n=56)$ were treated with a permanent pacemaker. Almost all $(98.1 \%, n=52)$ of the patients treated with pacemakers reported resolution of syncopal symptoms. One patient passed away shortly following a PPM implant due to asystole despite a reportedly normal functioning pacemaker [71]. Treatment of an underlying causative factor $(15.8 \%, n=16)$ was the second most common treatment modality. Treatment of an underlying gastrointestinal 


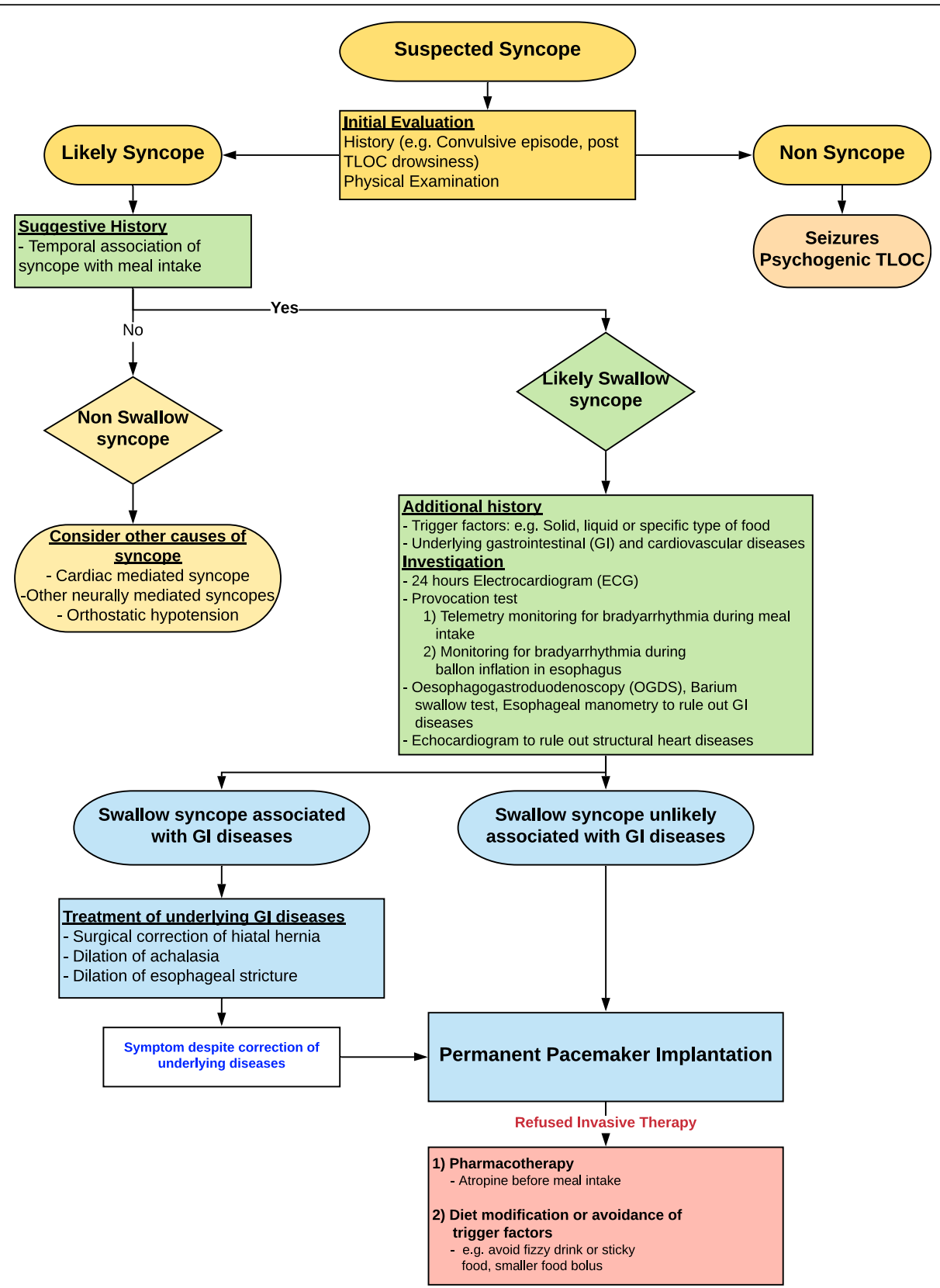

Fig. 4 Approach to the diagnostic work-up and management of patients with symptoms suggestive of swallow syncope

disorder has been shown to carry a good likelihood of resolving the swallow syncope. For example, all four cases of hiatal hernia that were corrected surgically had a complete resolution of the swallow syncope. Likewise, dilatation of an oesophageal stricture and an achalasia resulted in complete resolution of swallow syncope. Other reported successful treatments of underlying gastrointestinal diseases included surgical cauterisation of the vagal nerve, long term proton pump inhibitors and surgical excision of an oesophageal carcinoma. Pharmacological management was the preferred treat ment option in the 19th and early twentieth century prior to the era of pacemakers. From the limited numbers, atropine was the most widely used, with about $90 \%$ efficacy. Table 2.

Various mechanisms regarding the pathogenesis of swallow syncope have been postulated.

The most common postulated mechanism is increased and excessive vagal reflex activation during swallowing causing cardio inhibition [86]. During swallowing, the afferent impulses from the oesophageal plexus travel via the vagus nerve to the nucleus solitarius tract in the 
medulla oblongata. Subsequently, a corresponding signal that regulates involuntary peristalsis will travel down the parasympathetic efferent fibers through the oesophageal branch of the vagus nerve [87]. The presence of reflex arcs between afferent sensory fibers and efferent parasympathetic fibers of the cardiac branch results in inappropriate vagal activation with bradycardia, disturbance to the conduction system and hypotension secondary to vasodilation $[27,88]$. The exact mechanism remains to be elucidated, however, excessive parasympathetic stimulation to the heart seems to be the central mechanism. The fact that atropine, a potent anticholinergic agent, prevents bradyarrhythmia effectively in cases of swallow syncope supports the theory of excessive vagal stimulations [5, 29, 66, 79].

Abnormal oesophageal mechanoreceptors have been postulated to be the primary cause of swallow syncope in individuals with underlying structural and functional disorders of the gastrointestinal system. We demonstrated a reproducible cardio-inhibition with balloon inflation in the mid to lower oesophagus in our patient $[48,89]$. The bradyarrhythmia was terminated upon deflation of the balloon suggesting that mechanoreceptors in the midlower oesophagus may play a role in the pathogenesis of swallow syncope.

Investigations of neurally-mediated syncope should be tailored based on actual precipitants. While a tilt-table test confirmed the presence of a vasovagal response with reproduction of syncope, it did not demonstrate any periods of asystole. The diagnosis in this case was confirmed during OGD with cardiac monitoring and hence investigation with an OGD with haemodynamic monitoring should be considered for individuals with suspected swallow syncope. A diagram depicting a proposed approach to the diagnostic work-up and management of patients with symptoms suggestive of swallow syncope is depicted in (Fig. 4).

\section{Conclusions}

Swallow syncope is a rare cause for syncopal events and should be considered as part of the diagnostic workup. Pacemakers are a safe and efficacious therapeutic option for all patients with that condition. In patients with associated gastrointestinal disease, specific treatment of the underlying disease has a high likelihood of resolving the swallow syncope without the need for permanent pacing.

\section{Abbreviations}

AV block: Atrioventricular block; ECG: Electrocardiogram;

OGD: Oesophagogastroduodenoscopy; PPM: Permanent pacemaker

\section{Acknowledgments}

This publication was presented as an abstract at the European Society of Cardiology, Heart Failure 2019 and the World Congress on Acute Heart Failure, 25th - 28th May 2019, Athens, Greece.

\section{Authors' contributions}

KSSW and AL prepared the manuscript and are responsible for the overall content as guarantors. TMP and INH reviewed the manuscript. All authors read and approved the final manuscript.

Funding

Not applicable.

\section{Availability of data and materials}

The datasets used and/or analysed in the literature review are available from the corresponding author on reasonable request.

\section{Ethics approval and consent to participate}

Not applicable.

\section{Consent for publication}

Written informed consent was obtained from the patient for publication of this case report.

\section{Competing interests}

The authors declare that they have no competing interests.

\section{Author details}

${ }^{1}$ Department of Medicine/Cardiology, University Malaya Medical Centre, Kuala Lumpur, Malaysia. ${ }^{2}$ Department of Medicine/Geriatric, University Malaya Medical Centre, Kuala Lumpur, Malaysia. ${ }^{3}$ Department of Medicine/

Gastroenterology, University Malaya Medical Centre, Kuala Lumpur, Malaysia.

Received: 12 January 2019 Accepted: 31 July 2019

Published online: 07 August 2019

\section{References}

1. Parry SW, Tan MP. An approach to the evaluation and management of syncope in adults. Bmj. 2010;340:c880.

2. Omi W, et al. Swallow syncope, a case report and review of the literature. Cardiology. 2006;105(2):75-9.

3. Engelhardt W, Kotlarek F, von Bernuth G. Deglutition syncope in childhood with complete atrioventricular block. Am J Cardiol. 1986;58(11):1113-4.

4. Kahn A, Koepke LM, Umar SB. Deglutition syncope: a case report and review of the literature. ACG Case Rep J. 2015;3(1):20-2.

5. Sy AO, Plantholt S. Swallowing-induced atrioventricular block. South Med J. 1991;84(10):1274-5.

6. Padalia KJ, Padalia AJ, Parikh MG. Dysphagia, Hyperglycemia, and Presyncope. Dysphagia. 2018;33(6):866-8.

7. Tawk S, Desuter G, Jamali S. Recurrent syncope upon deglutition. J Belg Soc Radiol. 2018;102(1):55.

8. Yamaguchi $Y$, et al. Citrus fruits induced swallow syncope with atrioventricular block or sinus arrest. J Electrocardiol. 2018;51(4):613-6.

9. Lipar L, et al. Swallow syncope after whiplash neck injury. Heart Surg Forum 2018;21(2):E084-e086.

10. Van Damme A, De Backer T, Vanderheeren P. Swallow presyncope in an athletic patient caused by third-degree atrioventricular block. Acta Clin Belg. 2018;73(6):403-7

11. Aydogdu l, et al. Swallow-induced syncope in 5 patients: Electrophysiologic evaluation during swallowing. Neurol Clin Pract. 2017;7(4):316-23.

12. Patel N, et al. Deglutition syncope. Proc (Baylor Univ Med Cent). 2017;30(3):293-4.

13. Zaid EA, et al. Swallow-induced syncope and carotid sinus hypersensitivity: coincident or associated conditions? J Electrocardiol. 2017:50(4):523-5.

14. Bhogal $\mathrm{S}$, et al. Deglutition syncope: two case reports attributed to vagal hyperactivity. Case Rep Cardiol. 2017;2017:2145678.

15. Trinco P, et al. A case of swallow syncope. Rev Med Liege. 2016;71(7-8):360-3.

16. Islam Z, Warricker F, Shah BN. Swallow (deglutition) syncope. Postgrad Med J. 2016;92(1090):489-90.

17. Chhetri SK, Khan S, Nixon J. Swallow syncope unravelled by fizzy drink challenge. Qjm. 2016;109(5):341-2.

18. Hu TY, et al. Swallow-induced syncope: a case report of atrial tachycardia originating from the SVC. HeartRhythm Case Rep. 2016;2(1):83-7.

19. Manu S, Aziz PF. Syncope with swallowing. J Pediatr. 2016;172:209-11.

20. Aaberg AM, Eriksson AE, Madsen PL, Dixen U. Swallow syncope caused by third-degree atrioventricular block. BMJ Case Rep. 2015;2015.

21. Saitoh T, et al. Swallow syncope. Acute Med Surg. 2015;2(2):145-6. 
22. Erdogan $\mathrm{Hl}$, Gok H, Karanfil M. Swallowing-induced atrioventricular block and syncope in a patient with achalasia. Turk J Gastroenterol. 2015;26(1):75-6.

23. Garg S, et al. Swallow syncope: clinical presentation, diagnostic criteria, and therapeutic options. Saudi J Gastroenterol. 2014;20(4):207-11.

24. Shah R, et al. Dangerous cold beverages: a case of swallow syncope. Am J Med. 2014;127(7):e3-4

25. Witcik M, Meskin J. Pop and drop. Wmj. 2014;113(4):162-3.

26. Okahara A. Blackout during meals: a case report of swallow syncope due to sinus arrest. J Cardiol Cases. 2014;10(3):91-3.

27. Moore PK, et al. A case of swallow syncope. Tex Heart Inst J. 2013:40(5):606-7.

28. Lambiris I, Mendoza I, Helguera M, Escudero JB, Bonilla C. Thirty years of blackouts: a case report of swallow syncope. J Community Hosp Intern Med Perspect. 2013;3(1).

29. Rezvani M, Casillas SG, Antanavicius G. Swallow syncope after laparoscopic vertical sleeve gastrectomy. Surg Obes Relat Dis. 2013;9(5):e77-8.

30. Kim C, et al. A case of swallow syncope associated with cold beverage ingestion. Korean Circ J. 2012;42(3):212-5.

31. Knopke S, et al. Fainting during ingestion. Deglutition syncope. Hno. 2012; 60(3):279-81.

32. Foreman J, Vigh A, Wardrop RM 3rd. Hard to swallow. Am J Med. 2011; 124(3):218-20

33. Vanerio G. Syncope caused by huge hiatal hernia. Case Rep Cardiol. 2011; 2011:560734.

34. Mitra S, et al. Swallow syncope: a case report and review of the literature. Clin Med Res. 2011;9(3-4):125-9.

35. Leitman $M$, et al. A 37-year-old man with recurrent fainting: a short communication. Eur J Echocardiogr. 2010;11(7):E30.

36. Lee GY, et al. Deglutition syncope associated with ventricular asystole in a patient with permanent atrial fibrillation. Korean Circ J. 2010;40(2):99-101.

37. Endean ED, et al. Deglutition syncope: a manifestation of vagal hyperactivity following carotid endarterectomy. J Vasc Surg. 2010;52(3):720-2.

38. Casella F, et al. When water hurts. Pacing Clin Electrophysiol. 2009;32(11):e25-7.

39. Karamitsos TD, et al. Massive hiatus hernia impeding transoesophageal echocardiography in a patient with swallow-syncope syndrome. Hell J Cardiol. 2009;50(3):216-7.

40. Favaretto $E$, et al. An uncommon case of right-sided throat pain and swallow syncope. J Cardiovasc Med (Hagerstown). 2008;9(11):1152-5.

41. Bajwa S, et al. Swallow syncope: reflex or reflux? Postgrad Med J. 2008;84(989):160-2.

42. John C. Dangerous sandwiches. Lancet. 2008;372(9656):2164.

43. Fahrner A, et al. Swallow syncope. Eur J Emerg Med. 2008;15(2):122-3.

44. Patsilinakos SP, et al. Swallow syncope in a patient with esophageal stenosis caused by an ascending aorta aneurysm: differential diagnosis from postprandial hypotension: a case report. Angiology. 2007;58(1):126-9.

45. Tuzcu V, Halakatti R. Swallow syncope associated with complete atrioventricular block in an adolescent. Pediatr Cardiol. 2007;28(5):409-11.

46. Gawrieh S, et al. Swallow syncope in association with Schatzki ring and hypertensive esophageal peristalsis: report of three cases and review of the literature. Dysphagia. 2005;20(4):273-7.

47. Turan I, Ersoz G, Bor S. Swallow-induced syncope in a patient with achalasia. Dysphagia. 2005;20(3):238-40.

48. Kang $\mathrm{KH}$, et al. Cases of swallow syncope induced by the activation of mechanorecepters in the lower esophagus. Korean J Intern Med. 2005;20(1):68-71.

49. Cherukuri S, Gardner GM. Deglutition syncope. Otolaryngol Head Neck Surg. 2004:130(1):145-7.

50. Oishi Y, et al. Syncope upon swallowing caused by an esophageal hiatal hernia compressing the left atrium: a case report. Echocardiography. 2004;21(1):61-4.

51. Srivathsan K, Lee RW. Swallow syncope. Pacing Clin Electrophysiol. 2003; 26(3):781-2.

52. Maekawa T, et al. Unusual swallow syncope caused by huge hiatal hernia. Intern Med. 2002:41(3):199-201.

53. Gordon J, et al. Swallow syncope associated with paroxysmal atrial fibrillation. Eur J Cardiothorac Surg. 2002;21(3):587-90.

54. Shirayama T, et al. Swallowing syncope: complex mechanisms of the reflex. Intern Med. 2002;41(3):207-10.

55. Magadle R, et al. Recurrent deglutition syncope. Isr Med Assoc J. 2001;3(3):222-3.

56. Haumer $M$, et al. Transient swallow syncope during periods of hypoxia in a 67-year-old patient after self-extubation. Crit Care Med. 2000;28(5):1635-7.

57. Kakuchi H, Sato N, Kawamura Y. Swallow syncope associated with complete atrioventricular block and vasovagal syncope. Heart. 2000;83(6):702-4.
58. Deguchi K, Mathias CJ. Continuous haemodynamic monitoring in an unusual case of swallow induced syncope. J Neurol Neurosurg Psychiatry. 1999;67(2):220-2.

59. Olshansky B. A Pepsi challenge. N Engl J Med. 1999;340(25):2006.

60. Antonelli D, Rosenfeld T. Deglutition syncope associated with carotid sinus hypersensitivity. Pacing Clin Electrophysiol. 1997;20(9 Pt 1):2282-3.

61. Bellorini $M$, et al. Recurrent syncope during deglutition. An uncommon form of sinusal dysfunction. Arch Mal Coeur Vaiss. 1992;85(7):1039-41.

62. Shapira Y, Strasberg B, Ben-Gal T. Deglutition syncope with coexistent carotid sinus hypersensitivity. Chest. 1991;99(6):1541-3.

63. Kunimoto $S$, et al. A case of swallow syncope induced by vagovagal reflex. Jpn J Med. 1990;29(2):199-202.

64. Elam MP, et al. Swallow syncope associated with complete atrioventricular block: a case report and review of the literature. Mil Med. 1989;154(9):465-6.

65. Ausubel K, Gitler B. Swallow syncope in an otherwise healthy young man. Am Heart J. 1987;113(3):831-2.

66. Nakano T, et al. Swallow syncope after aneurysmectomy of the thoracic aorta. Heart Vessel. 1987:3(1):42-6.

67. Nakagawa S, et al. A case of swallow syncope induced by vagotonic visceral reflex resulting in atrioventricular node suppression. J Electrocardiol. 1987; 20(1):65-9.

68. Guberman A, Catching J. Swallow syncope. Can J Neurol Sci. 1986;13(3):267-9.

69. Kadish AH, Wechsler L, Marchlinski FE. Swallowing syncope: observations in the absence of conduction system or esophageal disease. Am J Med. 1986; 81(6):1098-100.

70. Golf S, Forfang K. Congenital swallowing-induced symptomatic heart block: a case report of a probably hereditary disorder. Pacing Clin Electrophysiol. 1986;9(4):602-5.

71. Armstrong PW, McMillan DG, Simon JB. Swallow syncope. Can Med Assoc J. 1985;132(11):1281-4

72. Kunis RL, et al. Deglutition syncope and atrioventricular block selectively induced by hot food and liquid. Am J Cardiol. 1985;55(5):613.

73. Drake $\mathrm{CE}$, et al. Visually provoked complete atrioventricular block: an unusual form of deglutition syncope. Am J Cardiol. 1984;53(9):1408-9.

74. Bortolotti M, Cirignotta F, Labo G. Atrioventricular block induced by swallowing in a patient with diffuse esophageal spasm. Jama. 1982;248(18):2297-9.

75. Golf S. Swallowing syncope. A case report. Acta Med Scand. 1977;201(6):585-6.

76. Waddington JK, et al. Letter: carcinoma of the oesophagus with "swallow syncope". Br Med J. 1975;3(5977):232

77. Wik B, Hillestad L. Deglutition syncope. Br Med J. 1975;3(5986):747.

78. Alstrup P, Pedersen SA. A case of syncope on swallowing secondary to diffuse oesophageal spasm. Acta Med Scand. 1973;193(4):365-8.

79. Lichstein E, Chadda KD. Atrioventricular block produced by swallowing, with documentation by his bundle recordings. Am J Cardiol. 1972;29(4):561-3.

80. Tolman KG, Ashworth WD. Syncope induced by dysphagia. Correction by esophageal dilatation. Am J Dig Dis. 1971;16(11):1026-31.

81. Sapru RP, et al. Syncope on swallowing. Br Heart J. 1971;33(4):617-22.

82. Ragaza EP, Rectra EH, Pardi MT. Intermittent complete heart block associated with swallowing as a complication of acute myocardial infarction. Am Heart J. 1970;79(3):396-400.

83. Sapru R. An unusual cause of syncope. Proc R Soc Med. 1968;61(10):955-6.

84. James AH. Cardiac syncope after swallowing. Lancet. 1958;1(7024):771-2.

85. Correll HL, Lindert MC. Vagovagal syncope; report of a case apparently induced by digitalization. Am Heart J. 1949;37(3):446-54.

86. Howland RH. Vagus nerve stimulation. Curr Behav Neurosci Rep. 2014;1(2):64-73.

87. Steele CM, Miller AJ. Sensory input pathways and mechanisms in swallowing: a review. Dysphagia. 2010;25(4):323-33.

88. Benditt DG. Neurally mediated syncopal syndromes: pathophysiological concepts and clinical evaluation. Pacing Clin Electrophysiol. 1997;20(2 Pt 2):572-84.

89. Carey BJ, de Caestecker J, Panerai RB. More on deglutition syncope. N Engl J Med. 1999:341(17):1316-7.

\section{Publisher's Note}

Springer Nature remains neutral with regard to jurisdictional claims in published maps and institutional affiliations. 